\title{
Applied and Professional Ethics
}

\author{
Göran Collste \\ Journal Article
}

\section{Tweet}

N.B.: When citing this work, cite the original article.

Original Publication:

Göran Collste, Applied and Professional Ethics, KEMANUSIAAN The Asian Journal of Humanities, 2012, 19(1), pp. 17-33.

Link to original publication: http://web.usm.my/kajh/vol19_1_2012.html

Copyright: The Authors and Kemanusiaan

KEMANUSIAAN The Asian Journal of Humanities

Postprint available at: Linköping University Electronic Press

http://urn.kb.se/resolve?urn=urn:nbn:se:liu:diva-77721 


\title{
Applied and Professional Ethics
}

\author{
GÖRAN COLLSTE \\ Linköping University, Linköping, Sweden \\ Goran.collste@liu.se
}

\begin{abstract}
The development of applied ethics in recent decades has had great significance for philosophy and society. In this article, I try to characterise this field of philosophical inquiry. I also discuss the relation of applied ethics to social policy and to professional ethics. In the first part, I address the following questions: (1) What is applied ethics? (2) When and why did applied ethics appear? and (3) How do we engage in applied ethics? What are the methods? In the second part of the article, I introduce professional ethics. What is professional ethics, and how can one distinguish professional ethics from applied ethics? I argue that the moral content of professional ethics is a result of professional relations. I also argue that professional ethics best can be understood as a type of virtue ethics.
\end{abstract}

Keywords and phrases: applied ethics, professional ethics, reflective equilibrium, moral principles, method

\section{Introduction}

Morality is a natural feature of human life. Human beings are social beings engaged in social interactions. As human beings, we cannot avoid making judgements about what is right and wrong, what one should do and what is valuable. We engage in ethics when we start to reflect on our moral judgements and actions: why is this behaviour right? What is the reason for this act? Can this act be justified? Hence, ethics is reflection on morality or, one might say, the theory of morality.

As human beings, we act in different capacities and roles. Moral judgements are made and moral acts performed in different social contexts, such as health care, politics, work and school. In health care, the moral issues are related in particular to life and death and human well-being: Are all lifesaving measures acceptable? Should we introduce screening for genetic diseases? In politics, judgements often concern value conflicts. The decision maker, for example, a politician or a civil servant, must choose an alternative that might promote one value at the expense of another: economic growth at the expense of sustainability, individual freedom at the expense of equality, etc. When we reflect on this type of decision making, we engage in applied ethics. Hence, applied ethics is concerned with crucial aspects of human life and social development. 


\section{Applied Ethics}

Applied ethics is the art or science of reflecting on moral dilemmas and moral problems in different social contexts. One of the most influential philosophers in the field of applied ethics, James Childress, defines applied ethics as follows:

The terms "applied ethics" and "practical ethics" are used interchangeably to indicate the application of ethics to special arenas of human activity, such as business, politics and medicine, and to particular problems, such as abortions. (Childress 1986)

The number of "special arenas" has constantly increased, and, hence, applied ethics is an expanding field. Medicine and health care were starting points, and politics and business followed. Now, more and more human activities are assessed from an ethical point of view: farming, animal breeding, technology, etc. Recently, I even came across a research project in "space ethics"! Since the 1970s, applied ethics has developed as a discipline with numerous subdisciplines: medical ethics, animal ethics, environmental ethics, business ethics, research ethics, technology and ethics, Information and Communication Technology (ICT)-ethics, politics and ethics, etc., each sub-discipline with its own conferences, journals and academic associations.

However, one phrase in Childress's definition warrants additional consideration. What does Childress mean when he says that applied ethics indicates "...the application of ethics to special arenas of human activity"? The expression mirrors perhaps an oversimplified, deductive view of applied ethics. The view that applied ethics is just an application of ethical theory to practical problems has been questioned by many authors. In contrast to Childress, these authors stress that for the sake of relevance, applied ethics presupposes an interplay between theory and practice, experience and reflection and intuitions and principles.

Tom Beauchamp suggests the following definition of applied ethics: "... 'applied ethics' refers to any use of philosophical methods to treat moral problems, practices, and policies in the professions, technology, government, and the like" (Beauchamp 2003, 3). However, he adds that also other methods can be used. In this article, I will show that research in applied ethics requires a multiplicity of methods. I will not question Beauchamp's definition; analysing ethics obviously implies using philosophical methods. However, against the background of the recent tendencies of multi-disciplinary research in applied ethics, attaining wellgrounded conclusions requires using various methods. 


\section{When and why did applied ethics appear?}

In a famous expression, philosopher Stephen Toulmin said that "Medicine saved the life of ethics" (Toulmin 1982). In the 1960s, the academic discipline of ethics was in decline. Most moral philosophers worked with conceptual and epistemological questions. Not many were engaged in normative ethics, and even fewer bothered to analyse moral problems in the real world. As a consequence, many people considered academic ethics a peculiar philosophical subject. In the early 1970s, the situation changed. Medicine saved the life of ethics; new and acute moral problems in medicine that had no ready-to-hand answers emerged. Ethicists were wanted once more.

Different reasons lie behind the development of applied ethics. Three of these reasons are as follows. During the 20th century, the Western world experienced a period of secularisation. Fewer and fewer people attended church, and fewer and fewer people asked for moral advice from the church. In the words of sociologist Max Weber, "moral heteronomy", whereby moral answers were provided by an authority, often the church, became "moral autonomy", whereby individuals themselves had to formulate answers. This development took place at a time when, in medicine and in other social arenas, new and difficult moral problems were arising: should limits be applied to pre-natal diagnostics? Should euthanasia be permitted? How should we address new genetic possibilities like stem-cell research and human cloning?

A second, complementary explanation of the development of applied ethics relates to new moral problems facing society as a consequence of new technologies. For example, in neonatal intensive care, the lives of extremely premature infants could be saved. However, in many cases, the babies were saved only to live short and handicapped lives. Where should the doctor set the limits of treatment? When should a baby be saved and when allowed to die? In another example, from another field, the development of computer technology has made possible the storage of more and more information, including personal information about individual people. However, this development may threaten the right to privacy. How should one find the right balance between the need for information and the protection of privacy?

The problems mentioned are examples of policy vacuums: we do not know how to handle the new situations, and we lack moral and legal concepts and principles to address them (Moor 1985). Thus, the rise of applied ethics can be explained by a need to fill policy vacuums.

Developments in the social sciences and the humanities often mirror social change. At the end of the 1960s and the beginning of 1970s, the student 
movement and the New Left challenged established society. Heated discussions took place on topics such as the Vietnam War, social injustices, poverty in the Third World, gender inequality and the maltreatment of animals. Many philosophers were engaged in these discussions. From this perspective, the development of applied ethics can be seen as a philosophical response to a new social environment.

I will illustrate the development of applied ethics in the 1970s by referring to three books published during the decade. These books can still be considered the three most important works in the modern history of applied ethics.

The first book is John Rawls's A Theory of Justice, published in 1971. A Theory of Justice is a comprehensive and theoretical investigation of the meaning and justification of justice. Partly in opposition to utilitarianism, Rawls argues for a neo-Kantian contract theory and ends up with two principles of justice that incorporate the meaning of justice. Furthermore, Rawls develops a method of justification of moral beliefs called "reflective equilibrium", which is still the most influential in the field. With the publication of $A$ Theory of Justice, justice became a key issue in applied ethics. The comments on and critiques of Rawls's theory number in the thousands.

The second contribution to applied ethics that I will refer to is Peter Singer's book Practical Ethics, published in 1979. ${ }^{1}$ In Practical Ethics, Singer discusses a number of topical moral issues from a utilitarian perspective. Among the issues discussed are war, poverty, abortion, euthanasia, the treatment of animals, etc. Singer argues in a compelling way, and he does not hesitate to draw radical and often also counterintuitive conclusions. Singer's critique of the principle of human dignity led to heated controversies, and he was, for some years, even banned from speaking publicly in Germany. The reaction of the German authorities to Singer's work showed that applied ethics has a strong social impact.

The third book is a contribution to medical ethics that is considered the modern classic in the field. One of the authors, Tom Beauchamp, is a utilitarian philosopher, while the other, James Childress, is a Kantian philosopher. One of the aims of the book, Principles of Biomedical Ethics, first published in 1977 (and followed by numerous new editions), was to construct ethical principles acceptable to people belonging to different moral traditions, religious backgrounds and having different philosophies. Beauchamp and Childress proposed the following four principles as a basis for moral decision making in medicine: the principle of non-maleficience, the principle of beneficence, the principle of respect for autonomy and the principle of justice. Other authors have applied the four principles to other areas in applied ethics, like research ethics and business ethics. 
Common to these three works in applied ethics is that each of them has influenced the discussion in applied ethics in a profound way. Thus, they can be considered "classics" in applied ethics.

\section{What was new?}

The turn to applied ethics took place in the 1970s and 1980s. The turn involved many philosophers changing their focus. Moral philosophers were traditionally engaged in analysing moral semantics and other issues in meta-ethics. Now, more and more philosophers worked with moral problems in society. However, the turn to applied ethics was not a turn away from issues in meta-ethics. The discussion about methods in applied ethics and about theories of justification has been lively, and different alternatives, such as principlism, specificism, casebased theories (casuistic) and Rawls's theory of reflective equilibrium, have been developed.

The turn to applied ethics was a turn from descriptive ethics to normative ethics. Many early 20th century philosophers believed that ethics as a philosophical discipline should be restricted to describing and analysing concepts and theories. For academic philosophers to engage in normative argumentation was not appropriate. For example, in his 1911 inaugural lecture, the Swedish philosopher Axel Hägerström emphasised that "Moral philosophy should not be a subject in morality but a subject about morality" (Hägerström 1966). Rawls and Singer took a different position. According to them, for an ethicist to take a stand on controversial issues is possible and legitimate. What is important is that the ethicist has good arguments.

However, one may still question whether the turn to applied ethics was something new. Brenda Almond argues that "...the inception of applied philosophy (including applied ethics) coincides with that of the Western philosophical tradition as a whole" (Almond 2000, 13). Remarkably, she mentions the pre-Socratic philosopher Thales (c.585 B.C.) as a pioneer in the field of ethics and economics. Other examples of important contributions to the history of applied ethics are works by Plato and Aristotle, philosophers who, among other things, worked in the areas of ethics and politics (for example, Plato's The Republic and Aristotle's Politics). Later philosophers engaged in applied ethics include Immanuel Kant, John Locke and John Stuart Mill, all of them inspiring authors for present-day ethicists.

Applied ethics also has roots in theological ethics. As classical examples, one can mention the theories of a just war of Augustine (5th century) and Aquinas (13th century). The conditions these theories set for a war to be judged just, namely, that the war must be fought with the right intentions, waged by a legitimate 
authority and aimed at redressing a wrong suffered, are still highly relevant in the present discussion on just war. Furthermore, Catholic and Protestant ethicists were amongst the first to engage in medical ethics (see, for example, Ramsey 1970 and Häring 1974).

\section{Methods}

A method is a way to achieve or come nearer to some end. A method is the road map that helps us to reach the goal. Hence, what methods we use depend on what we want to achieve. In science, the aim is to increase our knowledge. Something similar can be said of applied ethics. Ethical inquiry is a way to increase our knowledge of, or at least our insights into, ethical issues.

As a starting point, any type of ethical inquiry depends on conceptual clarity and a careful assessment of arguments. We need to know the relevant views concerning the question under inquiry. A critical interpretation of different views may be a sufficient aim in applied ethics. To know how different views are constructed is an end in itself.

However, inquiries in applied ethics often concern social practices and institutions, and the aim, in such cases, is to find a well-argued position from which to act. For this purpose, philosophical methods are not sufficient. We also need relevant factual information and methods from other disciplines.

Methods in applied ethics vary depending on the question under inquiry. Traditionally, the aim of inquiries in applied ethics is to come to justified moral positions or judgements regarding individual cases or principles. Different ethical theories will propose different methods to achieve this end. For example, utilitarianism suggests that we apply the principle of utility to judge what to do in a particular moral case. According to proponents of reflective equilibrium, the right action is the one that in a deliberative process matches relevant principles and considered judgements (Daniels 1996). I will illustrate the conflict between different positions in normative ethics with a much-discussed issue in recent bioethics: the question of how to address extremely premature infants, so called preemies (Bermudez 1996; Reblagiato et al. 2000).

Advances in perinatal medicine have dramatically improved neonatal survival in every industrialised country. Babies born in the 23rd to 24th week of pregnancy can now be saved. However, a great number of the babies who survive what is called "aggressive" treatment will have different types of persistent handicaps as a result of their early birth. In such cases, should it still be considered legitimate, or even a moral duty, to save such infants? 
When facing this type of dilemma, a decision can be made in different ways. Let me mention two extremes. In line with the traditional practices of the medical profession, one can let the doctor decide. Doctors have experience with this type of dilemma and have acquired a moral sensitivity and intuition that will help them to make a decision. Hence, the doctor decides with reference to praxis and previous, similar cases.

Another way to come to a decision is through applying a moral principle to the case in question. For example, a utilitarian philosopher can reason in the following way: When making moral decisions, one should choose the action that, compared with other alternatives, will increase the amount of pleasure or decrease the amount of pain in the world. Thus, in applied ethics, one shall always act in accordance with the principle of utility. Let us assume that in this particular case the life of the neonate will in total obviously produce more pain than pleasure. Thus, the correct moral solution is to let the neonate die. The decision is based on an application of a supposedly valid moral principle.

Good reasons exist for both these methods of decision making. The first method, the one used by the doctor, is anchored in medical practice. The doctor is here led by phronesis, to use Aristotle's concept. Through experience, personal experience and experience acquired through a tradition of professional practice, the doctor has acquired the skill to find the right solution after carefully examining the specific case. This type of decision is sometimes called intuitive. However, intuition is perhaps too vague a concept. Let us instead use the concept "considered judgement" to emphasise that this type of judgement is not the simple result of an accidental emotion.

However, this method of ethical decision making entails problems. In the case of perinatal treatment, the praxis of different doctors and different clinics varies, as the European Study on Parent's Information and Ethical Decision Making in Neonatal Intensive Care Units (EURONIC) clearly shows. Some doctors believe that they should use any technical means available to save the life of the child. Others think that, in some cases, non-treatment or euthanasia is a better alternative (Reblagiato et al. 2000). Who is right? When questioned, for example by an ethics committee charged with formulating rules for this type of decision, the doctors will not have much to say. The doctors can refer to intuition and practice and not much more.

The advantage to the second method, i.e., the philosopher's way of coming to a decision, is that, when questioned, a philosopher can point to some well-argued principles in defence of a decision. The utilitarian principle has a firm place in Western moral thinking and is thus, presumably, well founded. However, when this principle is applied to the specific case of saving or not saving a neonate, the 
decision is made at a distance and is unrelated to the specifics of the particular case. Such philosophy is, to use Ronald Dworkin's concept, made "from the outside in" (Dworkin 1993).

Now, what shall we do if the decision made by the doctor comes into conflict with the decision formulated by the philosopher? Which decision is more reasonable? When raising this question, we can relate our discussion to the method of reflective equilibrium (RE) (Rawls 1971; Daniels 1996).

Moral problem solving has to take different aspects of a case into consideration, and this type of problem solving often implies working at different levels of abstraction. Thus, relating different aspects of an ethical problem is central to the method of reflective equilibrium to achieve a fuller understanding of a case. In this way, RE is, by nature, inclusive. In the case just mentioned, the RE approach would be to invite, so to speak, the doctor and the philosopher into the process of finding a solution. The presupposition is, then, that both the doctor's considered judgement and the moral principles referred to by the philosophers are relevant inputs.

RE is a method for applied ethics, a method for doing what, however? Is RE a method for structuring argumentation in applied ethics, for decision making or perhaps a method for justification? The answer is that RE is a method used for all these purposes, although one may choose to use RE only for one or the other. When RE is used as a method for structuring argumentation, the point is to identify and relate different relevant aspects of a case. The moral intuitionist would, in the case of the neonates, say that the doctor's intuition is the only aspect of the case relevant to the decision. The moral principlist, on the other hand, would say that application of a principle is the only relevant procedure. From the point of view of RE, contextual intuitions at the particular level and moral principles are all relevant.

When using RE as a method for structuring ethical debates, one asks for all the relevant aspects of a case. What moral considerations, then, are relevant in the case of the neonates? So far we have two proposals. One is the doctor's considered judgement. The other is the principle of utility. However, we can easily identify other relevant moral considerations. The parents' views are one. To take the parents' views into consideration would be in line with the principle of autonomy. One could also apply moral principles other than the principle of utility and the principle of autonomy to the case: if one alternative action is to let the baby die, or even to euthanise the baby, the principle of human dignity seems, at least prima facie, to be a relevant principle. Of course, one also has to know the facts of the case, however, not just any facts. In our example, the neonate's prognoses for survival and for persistent suffering from impairment are important 
to know. How, then, can we decide what facts are relevant? The relevant moral intuitions and moral principles are the determining factors. For example, the eye colour of the baby is not relevant because the fact has no moral implications, while the possible impairment is relevant for anyone who sees human suffering as ethically significant.

So far, we have discussed RE as a method for structuring ethical argumentation and ethical discussions. Let us now use RE as a method for decision making. We have to decide what to do with the neonate. When facing this moral dilemma, coming to a decision is obviously a difficult task. The persons involved, i.e., the doctors, nurses, parents etc., may have different moral intuitions, and more than one moral principle is, prima facie, relevant. In addition to the principle of utility, which emphasises the relevance of the possibility of the neonate's suffering, the principle of autonomy would stress the parents' right to influence the decision. Furthermore, the principle of human dignity would, at least according to one common interpretation, say that human life is inviolable and, thus, that a moral obligation exists to save the neonate's life. With the RE-method, the task so far has been to identify and consider all the relevant aspects.

The next step is to come to a decision. One possible way to proceed is the following: Let us assume that according to the doctor's considered judgement the neonate should be saved. This view is presumably based on the doctor's experience with similar situations in which injured patients have been treated, although their future lives would involve suffering. This judgement coheres with the principle of human dignity (at least when interpreted to mean that human life is inviolable). On the other hand, saving the neonate will perhaps come into conflict with the principle of utility. Let us, then, go back to the case and examine the situation more closely. We assume that, in this particular case, the neonate will clearly not survive more than a few months. Further, the neonate will live this short life partly unconscious and with a good deal of suffering. Under these circumstances, would not allowing the neonate to die be a relief for the child? Yes, one could say, in this particular case, the doctor's intuition led astray and should be corrected by the principle of utility. However, what about the principle of human dignity? Does the principle of human dignity not forbid this alternative? Perhaps in this case, in line with Henry Richardson's suggestion, we should specify this principle (Richardson 2000). The specified principle of human dignity then reads: "Human life is inviolable (and thus a moral obligation exists to save it) except when what remains of it is a short period of severe suffering". The reflective process goes back and forth, from the particular intuitions to the moral principles and back again, etc. Finally, a standpoint is hopefully achieved where modified principles and considered judgements coincide, for instance, in a specified principle. The process of reflective equilibrium has come to an end. ${ }^{2}$ 
We have come to a decision; however, is this decision justified? Yes, if all morally relevant aspects are considered, all affected persons involved are listened to and their views are taken into account. That is, RE is inter-subjective, and if no new aspect is added that would upset the equilibrium, the decision is justified (Reuzel et al. 2001). This type of justification is provisional. However, in a plural society, we can achieve no better one.

Other approaches to applied ethics exist. One is "designing-in-ethics" (Van den Hoven 1997; Miller 2009). Here the question is how we could design institutions so that they realise values. For example, how could we design social institutions so that corruption is avoided? How could global institutions promote justice? As Rawls puts the matter, the basic structure, i.e., the political and economic institutions, is the subject of justice (Rawls 1971, 3).

The designing-in-ethics approach is not limited to political and social institutions but could also be applied to technical systems. Social constructivists insist that new technology is the result of social interests, forces and choices. Social constructivism has both descriptive and constructive implications. Social constructivism teaches us that technologies are not neutral but serve the interests of particular institutions and social groups. However, this insight may also have constructive and normative implications. If we believe that technology is not immutable and that new technology can be shaped according to human needs and values, technological development becomes an ethical challenge. The process of designing technology is intimately connected to questions of what a good life is and what values we want to realise.

The designing-in-ethics approach relies on various methods. For example, methods of sociological research are, together with philosophical methods, necessary for designing-in-ethics in social institutions. Additionally, methods in informatics are necessary for designing-in-ethics in computer systems (Van Gerwen 1996).

Becoming involved in multidisciplinary research is demanding for ethicists. First, they must be able to understand other disciplinary perspectives. They must also integrate findings from other disciplines in their own work. Finally, ethicists must find ways to contribute to the overall aim of a multidisciplinary research project, which means that they must make evident how the ethical perspective contributes to a fuller understanding of the problem at hand.

\section{Should the ethicist give moral guidance?}

What is the role of ethicists? Should they answer questions and make recommendations regarding specific decisions? Or should they only provide 
information about, for example, methods for decision making, relevant ethical principles and previous decisions in similar cases? Different ethicists answer this question differently. According to Peter Singer, nothing prohibits ethicists from arguing for particular positions in applied ethics, provided that they have good arguments. Singer himself argues vigorously for liberal immigration policies, for generous aid to poor countries, against hunting etc. (Singer 1977).

Ronald Dworkin advocates a less normative position. According to Dworkin, under the methodological programme of "philosophy from the inside out", the primary task of the ethicist is to listen to conflicting views, to interpret and even reconstruct them to grasp their ethical substance and clarify how they are related. Thus, according to Dworkin's view, the role of the ethicist is rather one of an interpreter and moderator than a judge (Dworkin 1993).

\section{Professional ethics}

Professional ethics emanates from moral reflection in work. A relation exists between applied ethics and professional ethics. One might even say that professional ethics mirrors applied ethics. The professional ethics of, for example, doctors, nurses and occupational therapists, has its counterpart in medical and health-care ethics. The professional ethics of businessmen has its counterpart in business ethics, etc. However, professional ethics and applied ethics have some inherent differences. Professional ethics is based on the practice of a profession, while applied ethics is primarily an academic endeavour.

Professional ethics is the ethics of professional life or, in other words, the ethics of work. Work can be defined as activity resulting in products or services performed for payment. What is then the difference between professional work and non-professional work? The following criteria for distinguishing professions are often mentioned:

1. Academic education,

2. Importance of services provided,

3. Professional degree,

4. Professional association,

5. Autonomy and

6. Ethical code or code of conduct.

From an ethical point of view, the fifth criterion, autonomy, is particularly important. For example, assembly-line work is not autonomous but, instead, managed by other persons, for example, by a manager or an engineer. The worker lacks autonomy. Therefore, the worker rarely makes any decisions or confronts ethical dilemmas while at work. In contrast, a doctor makes many decisions about 
diagnosis and treatments during a work day, decisions that are crucial to the life and well-being of patients.

However, one should not exaggerate the distinction between professional and non-professional work. With respect to autonomy, the differences are diminishing in modern work life. On the one hand, more and more work is being professionalised according to the above criteria. For example, due to modernisation and advanced technology, today many blue-collar workers require higher levels of education, which can increase their self-determination. On the other hand, a parallel development in the opposite direction towards less autonomy exists for many traditional professions. For example, health-care policies and regulations increasingly restrict the autonomy of doctors in public health care.

What, then, is the moral content of professional ethics? First are the moral norms and duties that are common to all or at least most professions. These norms and duties can be divided according to the relations that professionals have to other people:

1. Relations to people dependent on professional work and service These relations include, for example, relations between teacher and pupil, doctor and patient, salesmen and customer. Such relations generate professional moral norms, like honesty, fidelity, care and safety.

\section{Relations to workmates}

Almost all employees have workmates and colleagues. The relation between workmates generates professional moral norms of loyalty and solidarity.

3. Relations to employers

Much professional work is performed as employment regulated by a contract. A professional stands in relation to an employer. Even these relations generate moral norms, for example, loyalty and confidentiality.

Thus, different types of professional relations generate different moral norms. These norms provide the basic moral framework of a profession. However, the norms are valid prima facie. If the professional moral norm comes into conflict with other moral norms, for example, with common morality, they may be overridden. The following are some examples of this type of norm conflict. Assume a lawyer who has a special obligation to defend a client. The client is accused of premeditating a murder. However, the evidence in the case is not 
conclusive, and the lawyer has a chance to get the accused released. At the same time, the lawyer is convinced that if the accused person is set free, the murder will occur. How should the lawyer act? Should the lawyer use every means in the attempt to free the client? The example illustrates a conflict between, on the one hand, the lawyer's loyalty towards a client and, on the other hand, a general moral norm of protecting human life.

Even norms generated by the relation to an employer might come into conflict with external moral norms, which is illustrated by the following example. An engineer finds out that her company is secretly dumping waste in a neighbouring lake. Should she inform the authorities, even at the cost of being accused of being disloyal to the employer? Here, the norm of loyalty to one's employer conflicts with a general norm for avoiding harm.

The conflicts between professional norms and ordinary morality may be more or less difficult to solve. In this situation, having a professional organisation to consult is helpful, under the assumption, of course, that the professional organisation takes professional ethics seriously. Parallel to an increased interest in professional ethics, professional organisations have increasingly formulated their professional codes of ethics.

The oldest and most well-known professional code is the Hippocratic Oath for doctors, which dates from the 4th century B.C. The oath states, inter alia, that "I (the doctor) will prescribe regimens for the good of my patients according to my ability and my judgement and never do harm to anyone". The Hippocratic Oath is still the basis for doctors' professional ethics, although some of its content has been changed.

A professional code of ethics normally contains two parts. In one part, often an introduction, the common goal of the profession is stated. For example, the code of ethics of the Swedish Association of Engineers begins with the following statement: "The duty of the engineer is to improve technology and technical knowledge towards more efficient use of resources without detrimental effects". A second part contains rules for behaviour. For example, the Swedish Code of Ethics for Occupational Therapists states that occupational therapists work "...to improve the capability of patients to live a worthwhile life in accordance with their wishes and needs and in relation to the demands of society". A paragraph dealing with patient relations states, "The patient/client is entitled to be treated with respect", which means that:

- The therapist shall respect the right of the patient/client to a private life. 
- The therapist shall obtain such information only as is necessary for the treatment.

What, then, is the purpose and function of a professional ethical code? First, a professional ethical code can help and guide professionals facing difficult moral decisions. Second, such a code can be a reference for those professionals who want to act in a morally correct manner. When someone discovers that a colleague is acting morally wrong, a code of ethics is a point of reference. Third, a code can improve the professional ethical standard, which presumes, however, that discussion about the code is ongoing.

\section{Professional ethics as virtue ethics}

Professional ethics develops within a community of professionals. For older and established professions, professional ethics is the result of a tradition of moral thinking. A fundamental question is how to characterise a "good doctor" or a "good lawyer". From this perspective, professional ethics can be described as a type of virtue ethics.

Philosopher Alasdair MacIntyre has developed a theory of virtue ethics. The concept of virtue presupposes what MacIntyre calls a human practice and "internal goods". The internal goods are those goods that are constitutive of the practice. MacIntyre defines practice in the following way:

By practice I am going to mean any coherent and complex form of socially established cooperative human activity through which goals internal to that form of activity are realized in the course of trying to achieve those standards of excellence which are appropriate to, and partially definitive of, that form of activity, with the result that human powers to achieve excellence, and human conceptions of the ends and goods involved, are systematically extended. (MacIntyre 1982, 187)

Let us now apply MacIntyre's concepts to professional ethics. A profession is a type of "practice". Accordingly, standards of excellence and internal goods exist that are definitive of a profession. In their work, professionals aim at realising these standards and goods, which also give legitimacy to a particular profession, while answering the question: what is the point or aim of the profession? For example, what is the point of engineering? Engineers could, in line with the above-mentioned code of ethics, answer: the aim of engineering is "...to improve technology and technical knowledge towards more efficient use of resources without detrimental effects". 
To learn the standards and goods of a particular profession is partly a cognitive process. However, just knowing about them is insufficient. The professional has to acquire these standards and goods, which should become an integrated part of the professional's character. Acquired character traits are called virtues. According to MacIntyre,

A virtue is an acquired human quality the possession and exercise of which tends to enable us to achieve those goods which are internal to practices and the lack of which effectively prevents us from achieving any such goods (ibid, 191).

Hence, in accordance with our application of MacIntyre's concepts to professional ethics, professional virtues are those virtues that are necessary to realising the standards and goods of a profession. The good or virtuous professional is the one who has the capacity and the desire to live up to the standards to make the right decision in problematic moral situations. This capacity is acquired through reflective practice.

\section{Conclusion}

Interest in both applied ethics and professional ethics has increased during the last decades. Applied ethics is an academic discipline analysing moral problems in different social arenas. Applied ethics is often worked on in collaboration between philosophers and academics from other disciplines and with professionals who are affected by a moral problem. The development of professional ethics is, on the other hand, a response to moral problems facing professionals in their work.

The turn to applied ethics can basically be explained by three factors. First, due to secularisation, unquestionable moral authorities no longer exist. Moral decisions are taken autonomously, and, in the public discussion on moral issues, a demand for expertise in applied ethics exists. Second, through new technologies, for example, in health care, society faces new and difficult moral problems. A public discussion is needed on how to handle the new moral dilemmas. Third, many people are engaged in struggles for social justice, sustainability, animal rights and other causes. Applied ethics can contribute to the understanding of this type of topical social and political issue.

As an academic discipline, applied ethics needs theory and method. Reflective equilibrium is an influential method for analysis and justification in applied ethics. According to the method of reflective equilibrium, a valid moral judgement is one that in a deliberative process matches relevant principles and 
considered judgements. The method is inclusive and aims at inter-subjectivity. Another methodological approach is designing-in-ethics. This method focuses on how social institutions and technical systems can be designed so that they realise and promote social values.

Professional ethics mirrors applied ethics. However, professional ethics emanates from the moral experiences of professionals in their work. For example, healthcare professionals reflect on moral problems in medicine, engineers on the consequences of new technologies, etc. Amongst professionals, a common moral ground is needed. The development of professional codes is one way to formulate rules of behaviour together with co-professionals.

Professional ethics can also be seen as a type of virtue ethics. From this perspective, the aim of professional ethics is to develop the professional's moral character so that the professional's capacity to act according to reason and morality increases. ${ }^{3}$

\section{Notes}

1. Here one could also have mentioned Singer's book Animal Liberation, appearing two years earlier. However, Practical Ethics covers a wider spectrum of issues and has, I would argue, played a greater role. Additionally, a chapter in Practical Ethics deals with the questions elaborated in Animal Liberation.

2. In a critique of the TRIPS-agreement within WTO that protects intellectual property rights at the expense of poor patients in developing countries, I apply the method of specification in an argument for the priority of a right to health (Collste 2011).

3. An earlier version of this article was included in Perspectives on applied ethics. ed. Göran Collste. 2007. Studies in applied ethics, 10. Linköping: The Centre for Applied Ethics, Linköping University.

\section{References}

Almond, B. 2000. Applied ethics: The broad picture. In Applied ethics and reflective equilibrium. ed. Bo Petersson. No. 8. Linköping: Centre for Applied Ethics, Linköping University.

Beauchamp, T. L. and Childress, J. E. 1977. Principles of biomedical ethics. Oxford: Oxford University Press.

Beauchamp, T. L. 2003. The nature of applied ethics. In A companion to applied ethics. eds. R. G. Frey and C. H. Wellman. Oxford: Blackwell. 
Bermúdez, J. L. 1996. The moral significance of birth. Ethics 106(2): 378-403.

Childress, J. 1986. Applied ethics. In A new dictionary of Christian ethics. eds. J. Macquarrie and J. E. Childress. London: The Westminster Press.

Collste, G. 2011. Specifying rights: The case of TRIPS. Public Health Ethics 4(1): 63-69.

Daniels, N. 1996. Justice and justification: Reflective equilibrium in theory and practice. Cambridge: Cambridge University Press.

Dworkin, R. 1993. Life's dominion: An argument about abortion and euthanasia. London: HarperCollins.

Hägerström, A. 1966. Socialfilosofiska uppsatser. Stockholm: Bonniers.

Häring, B. 1974. Medical ethics. Middlegreen: Saint Paul Publishers.

MacIntyre, A. 1982. After virtue. London: Duckworth.

Miller, S. 2009. Research in applied ethics. Philosophia 37(2): 185-201.

Moor, J. 1985. What is computer ethics? Metaphilosophy 16(4): 266-275.

Ramsey, P. 1970. The patient as person: Explorations in medical ethics. New Haven: Yale University Press.

Rawls, J. 1971. A theory of justice. Oxford: Oxford University Press.

Reblagiato, M. and others. 2000. Neonatal end-of-life decision making. Journal of American Medical Association 284(19): 2451-2459.

Reuzel, R. P. B., van der Wilt, G. J., ten Have, H. A. M. J. and de Vries Robbe, P. F. 2001. Interactive technology assessment and wide reflective equilibrium. Journal of Medicine and Philosophy 26(3): 245-261.

Richardson, H. 2000. Specifying, balancing and interpreting bioethical principles. The Journal of Medicine and Philosophy 25(3): 285-308.

Singer, P. 1977. Animal liberation: Towards an end to man's inhumanity to animals. London: Granada Publishing. 1979. Practical ethics. Cambridge: Cambridge University Press.

Toulmin, S. 1982. How medicine saved the life of ethics. Perspectives in Biology and Medicine 25(4): 736-750.

Van den Hoven, J. 1997. Computer ethics and moral methodology. Metaphilosophy 28: 219-236.

Van Gerwen, J. 1996. Three methods in applied ethics. Ethical Perspectives 3(3): 184192. 